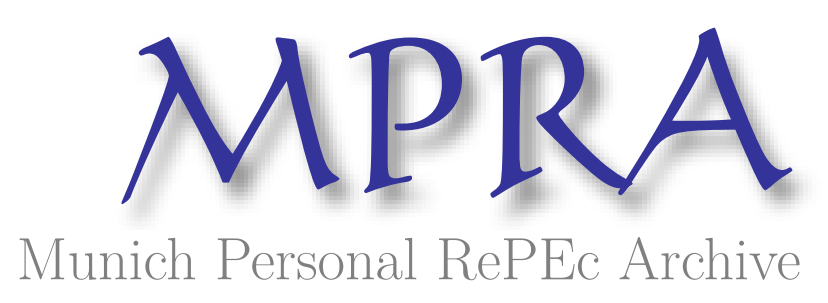

\title{
The Nature of Aggregate Demand and Supply Shocks in ASEAN Countries
}

\author{
Bashar, Omar H M N
}

Deakin University

22 December 2009

Online at https://mpra.ub.uni-muenchen.de/19881/

MPRA Paper No. 19881, posted 11 Jan 2010 17:16 UTC 


\title{
The Nature of Aggregate Demand and Supply Shocks in ASEAN Countries
}

\author{
Omar HMN Bashar*
}

\begin{abstract}
:
This paper revisits the issue of identification of macroeconomic shocks in ASEAN countries using an alternative identification scheme where the aggregate demand and supply shocks are allowed to be correlated. Applying the technique of Cover et al (2006) within a bivariate Structural VAR model, this paper showed that aggregate demand and supply shocks are interrelated (positively) in ASEAN countries. Unlike previous studies, it is found that changes in the output level are mainly driven by aggregate demand shocks, whereas supply shocks are playing the dominant role in affecting inflation in ASEAN countries. The correlations of the shocks across the countries are found to be quite small, suggesting that ASEAN is still not ready to form a common currency union like Europe.
\end{abstract}

Keywords: ASEAN, Aggregate Demand and Supply, Structural VAR, Blanchard-Quah Decomposition JEL Codes: C32, E31, E32

\footnotetext{
${ }^{*}$ School of Accounting, Economics and Finance, Deakin University, Australia
} 


\section{The Nature of Aggregate Demand and Supply Shocks in ASEAN Countries}

\section{Introduction}

For the purpose of designing and implementing appropriate macroeconomic policies, it is essential to identify various shocks and analyse their impacts on the economy. In particular, in the wake of recent global recession, it is time to reassess the conventional beliefs about the nature of macroeconomic shocks that are playing crucial roles in an economy. This paper revisits the issue of identification of macroeconomic shocks in ASEAN countries, using an alternative identification scheme where the aggregate demand (AD) and aggregate supply (AS) shocks are allowed to be correlated. The origin of the recession lies in the adverse aggregate demand shock and the persistence of current recession essentially depends on how the demand shocks affect an economy. If the demand shock has only temporary effects on the employment and output level, then we may expect an economy to recover quickly, even without any demand management policy.

The main question then is: Do aggregate demand shocks affect the output level permanently? Conventional macroeconomic analysis suggests 'No', and as a matter of fact, many previous prominent empirical studies were based on the assumption that the aggregate demand shock has only a temporary effect on output. The classic paper by Blanchard and Quah (1989) first applied this assumption within the SVAR framework in order to isolate a demand shock from the supply shocks. To date we can find a huge amount of literature that applied the Blanchard-Quah (BQ, henceforth) approach for the purpose of identifying macroeconomic shocks. The main idea is that the long run aggregate supply curve is vertical, and a shift in the aggregate demand curve will increase the inflation (or the price level) proportionately, but will not alter the output level.

The BQ technique further assumes that the shocks are uncorrelated. Recently Cover et al (2006) questioned this assumption, and using the US data, they showed that this assumption leads to a complete isolation in the dynamics of inflation and output. With demand and supply shocks being uncorrelated, changes in output were found to be driven mainly by the 
supply shocks and inflation by the demand shocks. Cover et al (2006) showed that this finding can be reversed if we allow the supply shock to be affected by the demand shock.

The main purpose of the current paper is to identify the aggregate demand and supply shocks in ASEAN region using the technique used in Cover et al (2006). Looking beyond the US data to a set of Southeast Asian countries will provide us more robust conclusions regarding the dynamics and interrelation of the shocks. Moreover, the examination of the shocks in ASEAN countries will help us analyse the prospects of forming a Euro-style currency union in the Southeast Asian region.

Essentially, the identification scheme used in this paper allows the case where a shift in the aggregate demand curve induces the long run aggregate supply curve to shift. The main question, however, remains: can an aggregate demand shock change the potential level of output, which in turn would shift the long run aggregate supply curve? The answer is 'yes', if the aggregate demand shock affects technology and productivity. There indeed exist a few significant literatures that draw attention to the role of demand in affecting innovation in technology in the production process and showed that an aggregate demand shock that raises the level of output temporarily can, through a number of channels, exert a permanent influence on the supply side. For example, Stadler (1990) argues that "....changes in the utilization of factor inputs when demand changes can result in reorganization and the acquisition of new skills; or a higher level of output may make innovation more profitable and result in the allocation of more resources to $R \& D ”$. With the use of theoretical models with endogenous technology, this study essentially showed that "Changes in the supply side of the economy are not independent of changes on the demand side". The empirical work of Utterback (1974) also points to the same idea, which showed that majority of the innovations in industry takes place in response to market demand conditions.

Lucas $(1972,1973)$ showed how an unanticipated change in money (an aggregate demand shock) could affect output. This effect occurs because firms misperceive the aggregate demand shock for the relative demand shock. However, this effect should not be persistent, as firms would have perfect information about the demand shock over time. Blanchard (1989) surveyed the literature on the effects of money on output and observed that if the initial misperception about the shock led firms or workers to change a state variable, which affect their decision in subsequent periods, then the initial changes in money or demand would have persistent effect. For instance, if the initial misperception leads the firms to invest in 
productivity enhancing technology, then we may expect a shift in the long run aggregate supply curve, which in turn will change the output level permanently.

The induced shift in the long run aggregate supply curve can also be explained by the concept

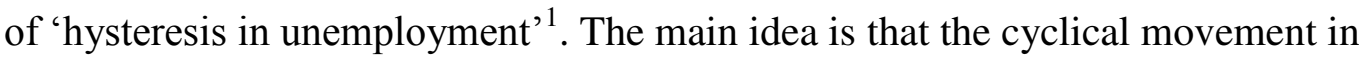
unemployment rate, which is mainly caused by demand shocks, may in fact cause the natural rate of unemployment to change. As the natural level of unemployment rate is related to an economy's long run employment, this in turn will shift the long run aggregate supply curve. Ball (1999), using the data from OECD countries showed that monetary policy and other determinants of aggregate demand have long run effects on unemployment. This implies that an aggregate demand shock may cause a supply shock by affecting the natural level of unemployment.

There are a few previous studies that attempted to analyse the nature of macroeconomic shocks in Southeast and East Asian countries. Examples include Bayoumi and Eichengreen (1994) and Ng (2002). These papers basically utilized basic BQ decomposition in order to identify the shocks and found that each type of shocks in different countries in Southeast and East Asia are highly correlated, in general. The main drawback of these studies is that they did not take into account the possibility that the aggregate demand and supply shocks can be interrelated. Thus the findings of these papers can be misleading if the shocks are actually correlated. For example, if the demand shocks invite some shocks to aggregate supply, then the identified supply shocks in BQ model would contain both the demand and supply components. And if this is the case we may see some ambiguity in the effects of an identified supply shock on inflation (as demand and supply shocks affect the inflation rate in opposite directions).

In the current paper I have used a bivariate SVAR model with long run restriction. However, unlike BQ strategy, I assumed that aggregate demand shock does not have any long run effect on output only when the shifting of aggregate demand curve does not induce the long run aggregate supply curve to shift. In other words, following Cover et al (2006), I have allowed the causality running from demand to supply shocks while imposing the long run neutrality restriction. Having been identified the shocks; I have shown that an aggregate demand shock may have a permanent effect on the output level in Southeast Asian Countries. I have also

\footnotetext{
${ }^{1}$ This term was first used formally by Blanchard and Summers (1987)
} 
shown that this strategy can help explain the anomaly in the effect of supply shocks on inflation observed in the BQ model.

Rest of this paper is organised as follows. In Section 2, basic results in the BQ model are reported. The data description and a few econometric issues involving VAR analysis are also explained in this section. In Section 3, using the AD-AS model introduced in Cover et al (2006), an attempt is made to explain how this model can be converted to a bivariate SVAR model where the demand and supply shocks are allowed to be correlated. Then the results of this modified model are discussed. Section 4 concludes the paper.

\section{BQ Model and the Output and Inflation Dynamics in ASEAN Countries}

\subsection{The BQ Approach}

Consider the following bivariate Structural VAR Model:

$$
A_{0} X_{t}=A_{1}(L) X_{t}+B \varepsilon_{t}
$$

where $\mathbf{X}_{\mathbf{t}}=\left(\Delta y_{t}, \Delta \pi_{t}\right)$, and $y$ and $\pi$ are measures of real output and inflation, respectively. ${ }^{2}$ Here $\boldsymbol{\varepsilon}_{\mathbf{t}}=\left(\varepsilon_{t}^{s}, \varepsilon_{t}^{d}\right)$, with $\varepsilon_{t}^{s}$ and $\varepsilon_{t}^{d}$ being one standard deviation supply and demand shocks, respectively. $\mathbf{A}_{\mathbf{0}}$ is a $2 \times 2$ matrix, $\mathbf{A}_{\mathbf{1}}(\mathbf{L})=\sum_{i=1}^{q} \mathbf{A}_{1 i} \mathbf{L}^{i}$ shows matrices of lag coefficients of the SVAR system. The BQ approach assumes that two shocks are not correlated, and hence, $\mathbf{B}$ is a diagonal matrix. Let us denote the diagonal elements in $\mathbf{B}$ by $b_{11}$ and $b_{22}$, which essentially are the standard deviations of the two shocks.

The structural shocks in (1) are not directly observable. It is the usual practice to estimate the reduced form VAR and use the estimated parameters and residuals in the reduced form VAR to retrieve the structural shocks. The reduced form VAR has the following form

$$
X_{t}=C(L) X_{t}+e_{t}
$$

\footnotetext{
${ }^{2}$ Here $y$ and $\pi$ are assumed to be I(1) and hence the VAR model uses first differences of the respective variables.
} 
with $\mathbf{C}(\mathbf{L})=\sum_{i=1}^{q} \mathbf{C}_{i} \mathbf{L}^{i}$ being the matrices of estimated lag coefficients and $\mathbf{e}_{\mathbf{t}}$ being the vector of two residual series. Equivalently, this reduced form VAR can be expressed in more simple way as

$$
\begin{aligned}
& \Delta y_{t}=\sum_{i=1}^{q} c_{11}^{i} \Delta y_{t-i}+\sum_{i=1}^{q} c_{12}^{i} \Delta \pi_{t-i}+e_{t}^{y} \\
& \Delta \pi_{t}=\sum_{i=1}^{q} c_{21}^{i} \Delta y_{t-i}+\sum_{i=1}^{q} c_{22}^{i} \Delta \pi_{t-i}+e_{t}^{\pi}
\end{aligned}
$$

The relation between the structural shocks and the reduced form VAR-residuals is crucial in identifying the structural shocks. This relation can be expressed as

$$
\mathbf{e}_{\mathrm{t}}=\mathbf{G}_{\mathbf{0}} \varepsilon_{\mathrm{t}}
$$

where $\mathbf{G}_{\mathbf{0}}=\mathbf{A}_{\mathbf{0}}^{-1} \mathbf{B}$ is a $2 \times 2$ matrix representing the contemporaneous effects of the one standard deviation shocks on the two variables.

It is straightforward to see that for above specifications, one cannot make a distinction between the supply and demand equations, and hence the two shocks, unless we impose some qualification(s) for defining the shocks. In order to separate out the demand shocks from the supply shocks, the BQ method defines a demand shock as the one that does not have any long run effect on the output level. If we denote $\mathbf{G}_{\mathbf{0}}$ as

$$
\mathbf{G}_{\mathbf{0}}=\left[\begin{array}{ll}
g_{11}^{0} & g_{12}^{0} \\
g_{21}^{0} & g_{22}^{0}
\end{array}\right],
$$

then the long run restriction essentially implies that

$$
g_{12}^{0}=-\frac{\sum_{i} c_{12}^{i}}{1-\sum_{i} c_{22}^{i}} g_{22}^{0}
$$

Imposition of this restriction makes the structural VAR system exactly identified, and one will now be able to identify the structural shocks, $\varepsilon^{s}$ and $\varepsilon^{d}$, by using the information from the estimated reduced form VAR. 


\subsection{Data Description and VAR Specification}

Taking into account the availability of data, I have considered 5 ASEAN countries for the SVAR analysis. They are Indonesia, Malaysia, The Philippines, Singapore and Thailand. Bivariate SVAR models have been estimated separately for each of these 5 ASEAN countries. The variables included in the VAR models are:

$d l y=$ Growth rate of real GDP. This variable is defined as $d l y=100\left[\ln \left(y_{t}\right)-\ln \left(y_{t-4}\right)\right]$, where $y$ denotes real GDP volume $(2000=100)$.

dinfl $=$ First difference of the log of inflation rate. The inflation rate is defined as infl $=100\left[\ln \left(P_{t}\right)-\ln \left(P_{t-4}\right)\right]$, where $P$ denotes the Consumer Price Index $(2000=100)$. The variable dinfl is defined as $\operatorname{dinfl}=\operatorname{infl}_{t}-$ infl $_{t-1}$.

The samples range from 1981:Q1 to 2008:Q4. DataStream, IMF and Abeysinghe and Rajaguru (2004) are the main sources of data. ${ }^{3}$ As the GDP data exhibits high seasonality, I applied Census X12 method on $y$ to de-seasonalize this series. ADF unit root test has been applied on $\ln (y)$ and infl (not reported here). For each of the countries, the test results suggested that we cannot reject the null of unit root unambiguously for $\ln (y)$ and infl. However, first differences of these variables have been found to be stationary ${ }^{4}$. To induce stationarity, I therefore use the first difference forms of $\ln (y)$ and infl in VAR models.

The VAR lag orders used for each country are provided in Table 1. To decide on the lag order, I looked at LR, AIC, SC, FPE and HQ criteria for up to 16 lags. As usual, these criteria suggested different lag orders. In general, SC suggests the shortest lag order, whereas AIC suggests the longest lag orders. From the suggested specifications by different criteria, I have

\footnotetext{
${ }^{3}$ For Malaysia, Indonesia and thailand, quarterly raw data for much earlier periods are not available. I thus depended on disaggregated quarterly series estimated in Abeysinghe and Rajaguru (2004) for these data.

${ }^{4}$ The finding that inflation is a nonstationary variable is somewhat contrary to the general perception that inflation is mean reverting. The intuition behind the nonstationarity of the inflation rate can be justified by the theory of 'optimal collection of seigniorage' proposed by Mankiw (1987). According to this theory inflation is one kind of tax on holding money balances. One would expect that an optimal fiscal policy involves smoothing of the tax rates over time. 'Just as the smoothing of consumptions by the consumers makes consumption a random walk, the smoothing of tax rate by the Government makes tax rate a random walk' (Mankiw 1987). Applying the same principle, the theory of optimal seigniorage suggests that inflation should be smoothened, and such smoothing essentially makes this series approximately a random walk.
} 
chosen the lowest lags that ensures the property of 'serially uncorrelated residuals' and this property has been verified mainly by examining the autocorrelograms of the residuals.

Table 1: VAR lag Specifications

\begin{tabular}{|l|c|}
\hline Country & VAR Lag Orders \\
\hline Indonesia & 9 \\
\hline Malaysia & 4 \\
\hline The Philippines & 10 \\
\hline Singapore & 5 \\
\hline Thailand & 11 \\
\hline
\end{tabular}

\subsection{Impulse Response Functions in the BQ Model}

The dynamic impacts of output and inflation to a positive one standard deviation demand and supply shocks in each of the 5 ASEAN countries are shown in figure 1 . As the VAR models use first-difference forms of output levels and inflation rates, here I have computed the accumulated responses of the changes in two variables to the shocks in order to see the dynamics of the variables in their levels. By construction, the output response in each country approaches to zero within a few quarters of the demand shocks in each country. In all the countries, the supply shocks appear to cause permanent increases in the output levels. In line with the conventional view, the demand shocks appear to have a permanent effect on the inflation rate in each of the 5 countries considered.

The main anomaly, however, is observed in the responses of the inflation rates to the positive supply shocks. Except for Indonesia, we observe that a positive supply shock causes the inflation rate to increase (instead of to decrease) in the long run. Indonesia is the only country which can justify the BQ decomposition in explaining the effects of an aggregate supply shock on the inflation rate.

For rest of the countries, this anomaly might have been caused by the fact that the identified supply shock in BQ model contains the demand component. In other words, part of the supply shocks (which is supposed to be an independent shock) is induced by a demand shock, and as positive demand shocks unambiguously increase the inflation rate, the net effect will depend on the relative magnitudes of the effects of demand and supply shocks. In the next Section it has been shown how we can resolve this anomaly by allowing the demand and supply shocks to be correlated. 
Figure 1: IRF's in the BQ Model:

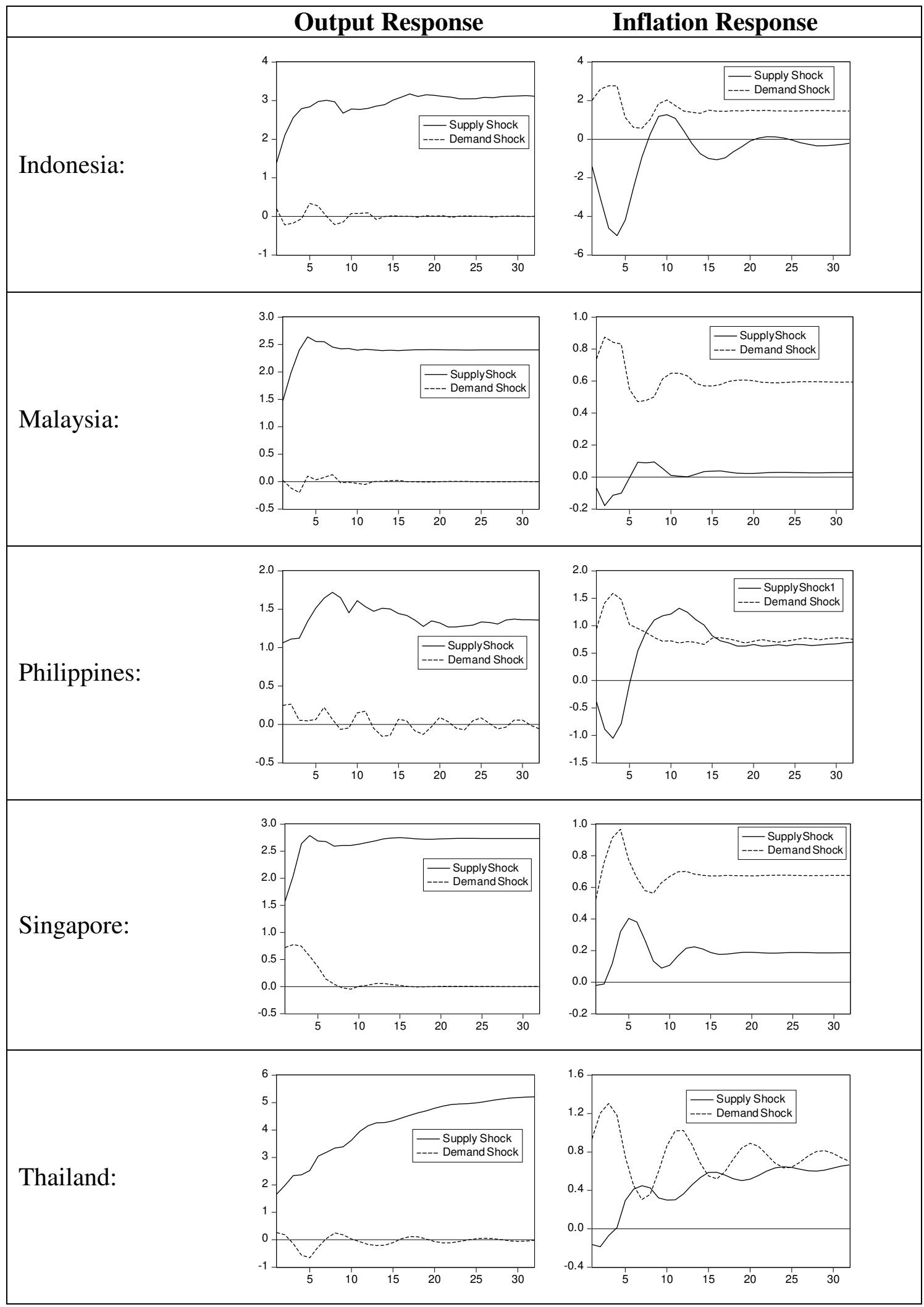




\section{Alternative Identification}

\subsection{The Model}

The identification scheme used here is based on a simple AD-AS model ${ }^{5}$ :

$$
\begin{aligned}
& y_{t}^{s}=E_{t-1}\left[y_{t}\right]+\alpha\left(\pi_{t}-E_{t-1}\left[\pi_{t}\right]\right)+v_{t}^{s} \\
& y_{t}^{d}+\pi_{t}=E_{t-1}\left[y_{t}^{d}+\pi_{t}\right]+v_{t}^{d} \\
& y_{t}^{s}=y_{t}^{d}
\end{aligned}
$$

Here, as before, $y$ and $\pi$ are measures of real output and inflation, while $v_{t}^{s}$ and $v_{t}^{d}$ are the supply and demand shocks, respectively. $E_{t-1}[\bullet]$ represents the expected value of a variable in period $\mathrm{t}$, given the set of information available at the end of period (t-1). The superscripts $s$ and $d$ represent supply and demand respectively.

The first equation is a version of Lucas Supply Curve, where real output depends on its expected value, unanticipated inflation and a random supply shock. The second equation represents a simple aggregate demand function, where aggregate demand (expressed in money term) consists of its expected value and a random aggregate demand shock. The third equation represents the equilibrium condition.

We can express the AS and AD shocks as $v^{s}=b_{11} \varepsilon^{s}$ and $v^{d}=b_{22} \varepsilon^{d}$, with $\varepsilon^{s}$ and $\varepsilon^{d}$ having unit variance and $\mathrm{b}_{11}$ and $\mathrm{b}_{22}$ being the standard deviation of actual shocks, $v^{s}$ and $v^{d}$. These expressions of shocks assume that the two shocks are uncorrelated to each other. If we allow supply shocks to be affected by the demand disturbances, then the two shocks can be represented as:

$$
\begin{aligned}
& v^{s}=\gamma\left(b_{22} \varepsilon^{d}\right)+b_{11} \varepsilon^{s} \\
& v^{d}=b_{22} \varepsilon^{d}
\end{aligned}
$$

\footnotetext{
${ }^{5}$ This model is similar to the one used in Cover et al (2006).
} 
Now the AS shock has two components; $b_{11} \varepsilon^{s}$ is the independent AS shock, whereas $\gamma\left(b_{22} \varepsilon^{d}\right)$ is the induced (by an independent AD shock) AS shock. The coefficient $\gamma$ measures the extent to which an AS shock is influenced by an AD shock.

If we assume that the expected value of output and inflation are just the actual respective values in the immediate last period; i.e.; if $E_{t-1}\left[y_{t}\right]=y_{t-1}$ and $E_{t-1}\left[\pi_{t}\right]=\pi_{t-1}$, then the above model (6) can be modified to

$$
\begin{aligned}
& \Delta y_{t}=\alpha \Delta \pi_{t}+\gamma\left(b_{22} \varepsilon^{d}\right)+b_{11} \varepsilon^{s} \\
& \Delta \pi_{t}=-\Delta y_{t}+b_{22} \varepsilon^{d}
\end{aligned}
$$

In general, the actual and expected values of output and inflation also depend on the sequences of past realizations of these variables. We can thus transform the above model to a standard Structural VAR form as

$$
\begin{aligned}
& \Delta y_{t}=\alpha \Delta \pi_{t}+\sum_{i=1}^{q} \phi_{y i} \Delta y_{t-i}+\sum_{i=1}^{q} \phi_{\pi i} \Delta \pi_{t-i}+\gamma\left(b_{22} \varepsilon^{d}\right)+b_{11} \varepsilon^{s} \\
& \Delta \pi_{t}=-\Delta y_{t}+\sum_{i=1}^{q} \theta_{y i} \Delta y_{t-i}+\sum_{i=1}^{q} \theta_{\pi i} \Delta \pi_{t-i}+b_{22} \varepsilon_{t}^{d}
\end{aligned}
$$

Having been specified the Structural VAR in (8) and the reduced form VAR in (3), it is now straightforward to show the following relationship between the reduced form VAR residuals $\left(e^{y}, e^{\pi}\right)$ and the unit variance structural shocks $\left(\varepsilon^{s}, \varepsilon^{d}\right)$ :

$$
\left[\begin{array}{l}
e^{y} \\
e^{\pi}
\end{array}\right]=\left[\begin{array}{cc}
1 & -\alpha \\
1 & 1
\end{array}\right]^{-1}\left[\begin{array}{cc}
b_{11} & \gamma b_{22} \\
0 & b_{22}
\end{array}\right]\left[\begin{array}{l}
\varepsilon^{s} \\
\varepsilon^{d}
\end{array}\right]
$$

which can be simplified to obtain:

$$
\left[\begin{array}{l}
e^{y} \\
e^{\pi}
\end{array}\right]=\frac{1}{1+\alpha}\left[\begin{array}{cc}
b_{11} & (\alpha+\gamma) b_{22} \\
-b_{11} & (1-\gamma) b_{22}
\end{array}\right]\left[\begin{array}{l}
\varepsilon^{s} \\
\varepsilon^{d}
\end{array}\right]
$$

The variance-covariance matrix of the reduced form VAR residuals can be defined as 


$$
\left[\begin{array}{cc}
\operatorname{var}\left(e^{y}\right) & \operatorname{cov}\left(e^{y}, e^{\pi}\right) \\
\operatorname{cov}\left(e^{y}, e^{\pi}\right) & \operatorname{var}\left(e^{\pi}\right)
\end{array}\right]=\left[\begin{array}{cc}
\frac{b_{11}}{1+\alpha} & \frac{(\alpha+\gamma) b_{22}}{1+\alpha} \\
\frac{-b_{11}}{1+\alpha} & \frac{(1-\gamma) b_{22}}{1+\alpha}
\end{array}\right]\left[\begin{array}{cc}
\frac{b_{11}}{1+\alpha} & \frac{-b_{11}}{1+\alpha} \\
\frac{(\alpha+\gamma) b_{22}}{1+\alpha} & \frac{(1-\gamma) b_{22}}{1+\alpha}
\end{array}\right]
$$

The three elements in the left hand side of (11) can be obtained from the estimated reduced form residuals. However, there are four elements in the right hand side to be retrieved from these three left hand side elements. Technically that is how the identification problem arises and we need to impose a restriction to solve this identification problem. This additional restriction comes from the $\mathrm{BQ}$ long run restriction, which in this case states that the aggregate demand shock does not have any long run effect on the output level as long as this does not induce the long run aggregate supply curve to shift. Following Cover et al (2006), with reference to Structural VAR system (8) and reduced for VAR system (3), this restriction essentially implies that

$$
\alpha=-\frac{\sum_{i} c_{12}^{i}}{1-\sum_{i} c_{22}^{i}}
$$

As a matter of fact, we are assuming a vertical long-run aggregate supply curve, however, we are not ruling out the case in which the long-run aggregate supply curve may shift due to a shift in aggregate demand curve. Now the value of $\alpha$ from (12) can be substituted in (11) to solve for the remaining three parameters.

\subsection{Estimated parameters}

Based on (12), I have computed $\alpha$ from the estimation of reduced form VARs for each of the 5 countries. Here $\alpha$ is a measure of slope of the short run aggregate supply curve. The higher the $\alpha$, the larger will be the effect of changes in inflation on aggregate supply in the short run (A flatter AS curve). Table 3 below reported the computed values of $\alpha$ in 5 ASEAN countries 
Table 3: Computed Slopes of the Short Run Aggregate Supply Curve

\begin{tabular}{|c|c|c|c|c|}
\hline Indonesia & Malaysia & Philippines & Singapore & Thailand \\
\hline 0.099 & 0.029 & 0.26 & 1.389 & 0.278 \\
\hline
\end{tabular}

Except for Singapore, the computed $\alpha$ is very small, suggesting a relatively steeper short run aggregate supply curve for these countries. In Singapore, $\alpha$ is greater than 1, which suggests that an aggregate demand shock would have larger effect on output and smaller effects on inflation in the impact period, provided that $\mathrm{AD}$ shock is not correlated with the supply shock. However, this need not be the case in our modified model, as we have allowed for correlation between the demand and supply shocks.

Table 4 shows the estimates of the rest of the three coefficients for each of the 5 ASEAN countries. Except for Indonesia, it is observed that $\gamma$ is significantly positive, implying that a demand shock affects the supply shocks in the same direction. The estimates of $\gamma$ in these four countries range between 0.42 and 0.81 . A shift in the aggregate demand curve causes the largest shift in the aggregate supply curve in Malaysia and smallest shift in the Philippines. Accordingly, remaining other things same, we may observe a larger effect of AD shock on the output level in Malaysia, and relatively smaller effect in the Philippines.

Table 4: Estimated Coefficients

\begin{tabular}{|l|c|c|c|}
\hline & $\gamma$ & $b_{11}$ & $b_{22}$ \\
\hline Malaysia & $0.81(0.04)$ & $0.70(0.05)$ & $1.60(0.11)$ \\
\hline Singapore & $0.62(0.05)$ & $1.01(0.07)$ & $1.99(0.14)$ \\
\hline Thailand & $0.69(0.04)$ & $1.07(0.07)$ & $1.92(0.13)$ \\
\hline Philippines & $0.42(0.06)$ & $1.01(0.07)$ & $1.37(0.10)$ \\
\hline Indonesia & $-0.01(0.07)$ & $1.53(1.11)$ & $2.21(0.16)$ \\
\hline
\end{tabular}

Notes: Figures in parentheses are relevant standard errors.

Indonesia is the only country for which we observe a negative coefficient ${ }^{6}$ (though insignificant). However, this negative sign, to some extent, helps us explain the response of inflation to a supply shock in Indonesia observed in the BQ model. It can be recalled that Indonesia exhibited the right (negative) long run response of inflation to a positive supply shock. In BQ model, we didn't see any anomaly for Indonesia either because the correlation

\footnotetext{
${ }^{6}$ It is hard to explain the negative correlation between demand and supply shocks. It may be quite interesting to analyse the case of Indonesia individually to explore this issue further. One possible explanation could be that during the recession, economic agents re-evaluate their past decisions and mistakes, and based on this, adopt better organizational and managerial system, which may in turn increase the productivity in the long run.
} 
between the AD and AS shocks is insignificant or simply because both positive supply and negative demand shocks work in the same direction in affecting inflation.

The sizes of the shocks as measured by their respective standard deviations are found to be quite large, compared to what were claimed in the previous studies on ASEAN. The standard deviation of the aggregate demand shocks is found to be higher than that of aggregate supply shocks, in general. The mean of the aggregate demand shock is 1.82, whereas the corresponding figure for the aggregate supply shocks is only 1.06. This finding suggests that a demand shock is much more volatile than a supply shock in ASEAN countries. Indonesia is appeared to be facing the largest shocks, as this country has the largest standard deviations for both AS and AD shocks. In terms of both AD and AS shocks, Singapore and Thailand are exposed to the shocks that are of similar size. The size of the AS shock in the Philippines is also similar to that of Singapore and Thailand. Malaysia and the Philippines are experiencing the smallest AS and AD shocks, respectively.

\subsection{Impulse Response Functions and Variance Decompositions}

Figure 2 and 3 below show the impulse responses of output and inflation to a one standard deviation aggregate demand and supply shocks, respectively. The 95 percent confidence intervals of the responses are also shown in the figures. The responses of output to the supply shocks and inflation to the demand shocks are qualitatively similar to those in BQ model. A positive supply shock has permanent effect on output and a positive demand shock has a permanent positive effect on inflation. However, compared to the BQ model, the responses of output to demand shocks and inflation to supply shocks are quite different in this modified model.

For majority of the countries, we observe that an aggregate demand shock leads to a permanent shift in the output level. This is in line with our earlier postulation that suggests that a positive aggregate demand shock induces the long run aggregate supply curve to shift rightward and causes the output level to increase permanently. Again Indonesia shows the almost zero response of output to a demand shock, which, given our insignificant estimate of $\gamma$, is not surprising.

The most striking contribution of this modified model is visible in the response of inflation to the aggregate supply shocks. The point estimation of long run response of inflation to the 
aggregate supply shock is negative for majority of the countries. The point estimates of the long run responses of inflation to a supply shock in the Philippines are still positive, however, the responses are insignificant and much smaller compared to those in the BQ model. The positive response of inflation to a positive supply shock, which we observed for Singapore and Thailand in the BQ model, has disappeared in this modified model. The negative long run response is even significant in Malaysia and Singapore. This finding suggests that this alternative identification scheme is able to isolate the demand and supply shocks in some what better way than what the BQ model does. 
Figure 2: IRFs to a one Standard Deviation Aggregate Demand Shock

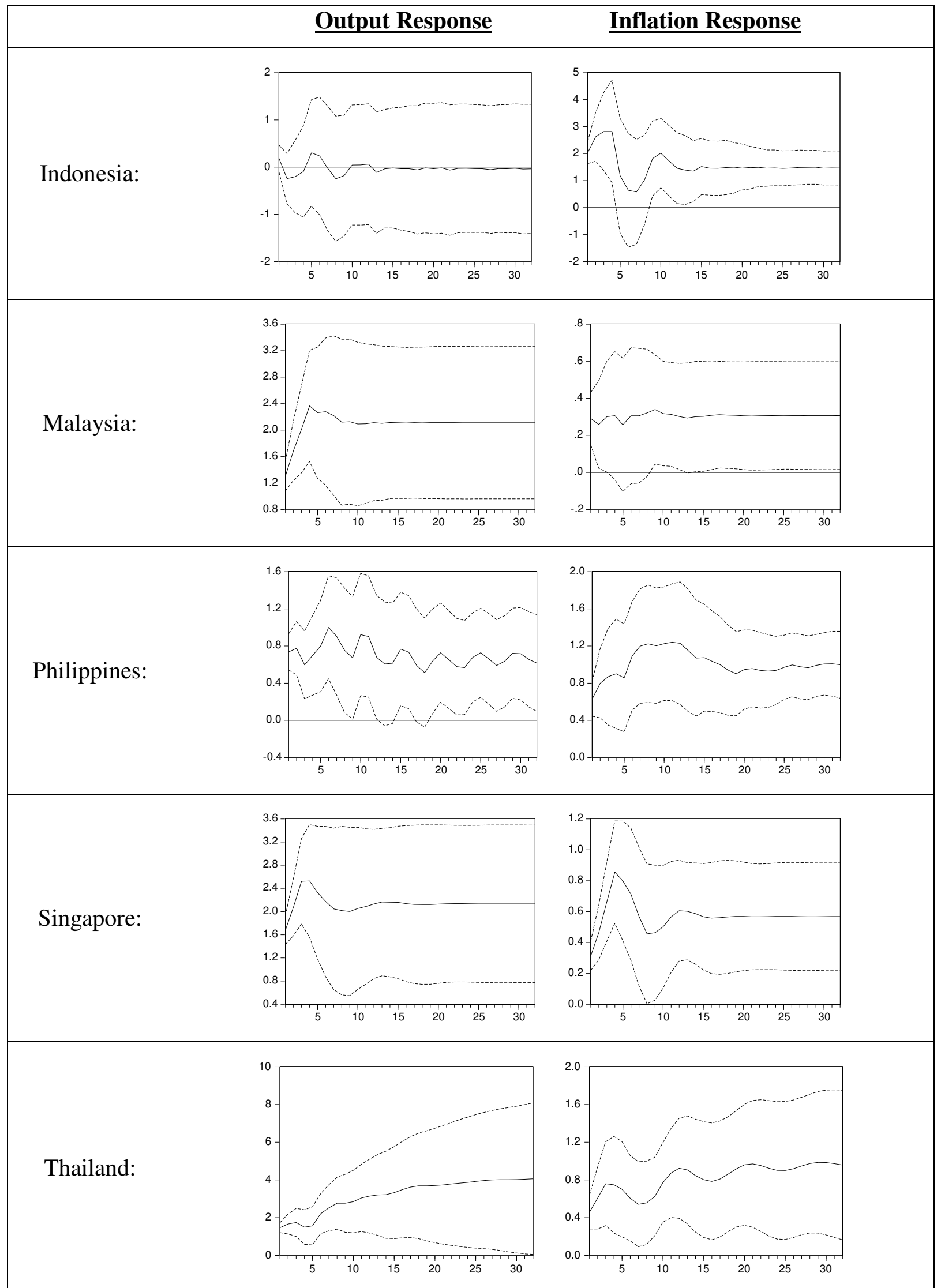

Note: The solid lines give the estimates of the accumulated responses of the changes in respective variables, while the dotted lines represent the bootstrap 95 percent confidence bound. 
Figure 3: IRFs to a one Standard Deviation Aggregate Supply Shock

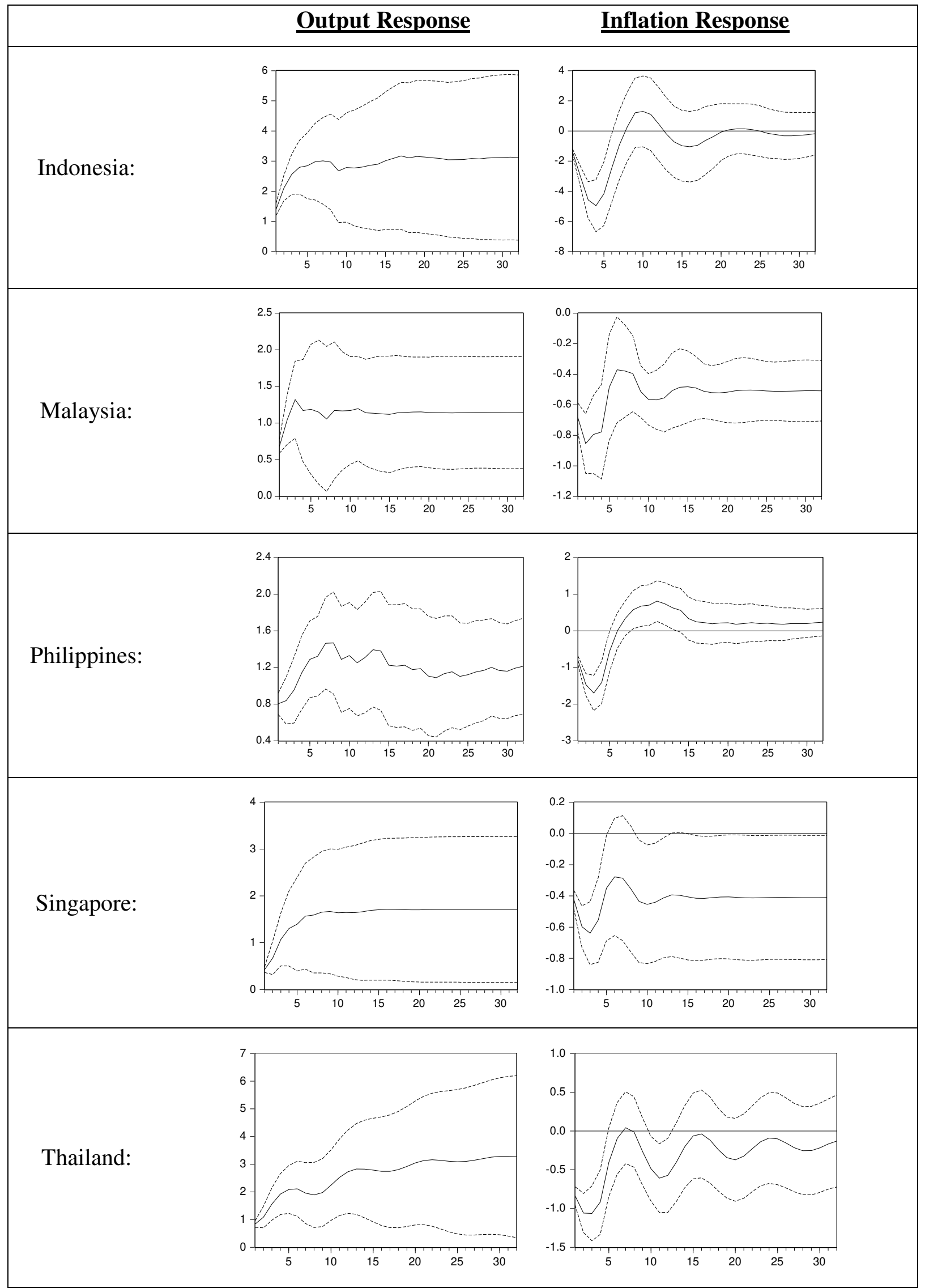

Note: The solid lines give the estimates of the accumulated responses of the changes in respective variables, while the dotted lines represent the bootstrap 95 percent confidence bound. 
The variance decomposition results reported in Table 5 suggest that aggregate demand shock has larger contribution in the variation of changes in output than what were reported in most of the studies that applied BQ decomposition. Cover et al (2006) has also pointed out to this issue and reported the similar results for the USA. As can be seen in table 5, in Malaysia, Singapore and Thailand demand shocks can explain larger share of the error variances in output fluctuations. In the Philippines both supply and demand shocks contributed quite a substantial portion of the variations in output. Again Indonesia is the only exception, where a supply shock is the dominant factor in explaining the output error variance. The variance decompositions of the changes in inflation suggest that the supply shocks account for larger variations in the changes in inflation in all the 5 ASEAN countries.

Table 5: Variance Decompositions in the Modified Model

\begin{tabular}{|l|c|cc|cc|}
\hline & Period & \multicolumn{2}{|c|}{ Variance Decomposition } & & \multicolumn{2}{c|}{$\begin{array}{c}\text { Variance Decomposition } \\
\text { Supply due to }\end{array}$} & $\begin{array}{c}\text { Demand } \\
\text { of } \text { dinfl due to } \\
\text { Supply } \\
\text { Shock (\%) }\end{array}$ & $\begin{array}{c}\text { Demand } \\
\text { Shock) }\end{array}$ & Shock (\%) & Shock $(\%)$ \\
\hline \multirow{2}{*}{ Indonesia } & 1 & 98.32 & 1.68 & 32.07 & 67.93 \\
& 32 & 82.55 & 17.45 & 66.44 & 33.56 \\
\hline \multirow{2}{*}{ Malaysia } & 1 & 21.46 & 78.54 & 84.66 & 15.34 \\
& 40 & 25.57 & 74.43 & 86.86 & 13.14 \\
\hline \multirow{2}{*}{ Philippines } & 1 & 54.36 & 45.64 & 61.91 & 38.09 \\
& 40 & 47.62 & 52.38 & 82.76 & 17.24 \\
\hline \multirow{2}{*}{ Singapore } & 1 & 5.97 & 94.03 & 64.61 & 35.39 \\
& 32 & 13.22 & 86.78 & 52.76 & 47.24 \\
\hline \multirow{2}{*}{ Thailand } & 1 & 24.58 & 75.52 & 76.93 & 23.07 \\
& 40 & 32.62 & 67.38 & 81.36 & 18.64 \\
\hline
\end{tabular}

Table 6 reports the simple correlations of the AD shocks in 5 ASEAN countries. In general, the correlation coefficients are considerably small compared to what were reported in similar previous studies on ASEAN countries. In terms of statistical significance, one may establish some kind of relation between the demand shocks in Malaysia, Philippines, Thailand and Singapore. However, the largest coefficient obtained is only 0.31 , and based on these small numbers, it cannot be concluded that the aggregate demand shocks are synchronized in the ASEAN countries. Table 7 reports the corresponding correlations for supply shocks. The situation is even worse in the case of aggregate supply shocks. Even though there are a few significant correlation coefficients, none of these are greater than 0.25 . 
Table 6: Correlation of the Demand Shocks

\begin{tabular}{|c|c|c|c|c|c|}
\hline & Indonesia & Malaysia & Philippines & Singapore & Thailand \\
\hline Indonesia & $\begin{array}{l}1.00 \\
-----\end{array}$ & & & & \\
\hline Malaysia & $\begin{array}{c}0.03 \\
(0.73)\end{array}$ & $\begin{array}{l}1.00 \\
-----\end{array}$ & & & \\
\hline Philippines & $\begin{array}{l}-0.028 \\
(0.79)\end{array}$ & $\begin{array}{c}0.31 * * * \\
(0.002)\end{array}$ & $\begin{array}{l}1.00 \\
-----\end{array}$ & & \\
\hline Singapore & $\begin{array}{c}0.06 \\
(0.54)\end{array}$ & $\begin{array}{c}0.30 * * * \\
(0.003)\end{array}$ & $\begin{array}{c}0.28 * * * \\
(0.005)\end{array}$ & $\begin{array}{l}1.00 \\
-----\end{array}$ & \\
\hline Thailand & $\begin{array}{c}0.01 \\
(0.89)\end{array}$ & $\begin{array}{c}0.29 * * * \\
(0.005)\end{array}$ & $\begin{array}{c}0.24 * * \\
(0.02)\end{array}$ & $\begin{array}{c}0.28 * * * \\
(0.005)\end{array}$ & $\begin{array}{l}1.00 \\
----\end{array}$ \\
\hline
\end{tabular}

Note: Figures in parantheses are the respective p-values. The 5\% and $10 \%$ significance levels are indicated by $* * *$ and $* *$, respectively.

Table 7: Correlation of the Supply Shocks

\begin{tabular}{c|ccccc}
\hline \hline & Indonesia & Malaysia & Philippines & Singapore & Thailand \\
\hline Indonesia & 1.00 & & & & \\
& ---- & & & & \\
Malaysia & 0.10 & 1.00 & & & \\
& $(0.32)$ & ---- & & & \\
Philippines & 0.05 & 0.16 & 1.00 & & \\
& $(0.63)$ & $(0.12)$ & ----- & & \\
Singapore & -0.06 & 0.028 & -0.03 & 1.00 & \\
& $(0.54)$ & $(0.78)$ & $(0.76)$ & ---- & \\
Thailand & $0.19 *$ & $0.21 * *$ & $0.25^{* * *}$ & 0.15 & 1.000000 \\
& $(0.07)$ & $(0.04)$ & $(0.01)$ & $(0.15)$ & ----- \\
\hline \hline
\end{tabular}

Note: Figures in parantheses are the respective p-values. The $1 \%, 5 \%$ and $10 \%$ significance levels are indicated by a $* * *, * *$ and $*$, respectively.

These numbers are much smaller than similar previous studies. For example, Bayoumi and Eichengreen (1994) reported that the correlation of aggregate supply shocks between Malaysia and Indonesia is 0.52 and that between Malaysia and Singapore is 0.71 . The same study reported corresponding figures for demand shocks as 0.58 and 0.67 , respectively. The correlation coefficients reported in Bayoumi et al (2000) are also larger than the ones 
reported in the current paper. That paper found that "Disturbances are highly correlated across certain ASEAN countries", and based on this, claimed that "Evidence on macroeconomic disturbances does not obviously indicate that ASEAN is further than Europe from satisfying the symmetrical-disturbances criterion". The small correlation coefficients obtained in the current paper are in sharp contrast with the findings in these studies and suggest that ASEAN region is still far away from meeting the requirements for a common currency union.

\section{Conclusion}

This paper utilizes the identification scheme proposed by Cover et al (2006) to examine the nature of aggregate demand and supply shocks in 5 ASEAN countries. It is found that the aggregate demand and supply shocks are positively correlated in Malaysia, the Philippines, Singapore and Thailand. The aggregate demand shock is found to be playing the dominant role in affecting the output levels in both short and long run in these countries. This finding is contrary to the conventional belief that the aggregate demand shock has only temporary effect on the output level. The identification scheme applied here allows the shocks to be transmitted from the demand to the supply side and the findings of the paper suggest that a shift in the aggregate demand curve may have induced the long run aggregate supply curve to shift in the same direction in these countries.

This paper further extend the analysis of Cover et al (2006) to show that the BQ approach may lead to anomalies in the identification of macroeconomic shocks, if we don't allow the correlation between the two shocks. It showed that in the BQ model, the identified aggregate supply shock leads to the positive responses in inflation, which is hard to justify by any macro theory. This anomaly is basically caused by the fact that aggregate demand and supply shocks are correlated. This is likely that the identified supply shocks in the BQ model contains some demand driven component, which causes the inflation rate to go up (instead of going down), when there is a positive supply shock. This paper showed that the apparent anomaly in the inflation dynamics disappears when we allow the correlation between the two shocks and the causality running from demand to supply shocks. 
It is also found that the supply shocks are playing the dominant role in affecting the inflation rate in ASEAN countries. This finding is also somewhat contrary to the conventional belief that inflation is always a monetary phenomenon. We even observed that the supply shock has a permanent effect on inflation in Malaysia and Singapore.

The finding of this paper has important policy implication, especially, in the wake of recent global recession. The finding that a shift in the aggregate demand curve induces a shift in the long run aggregate supply curve simply asserts that because of the recession an economy will reach the higher level of unemployment and lower level of output permanently if no policy action is taken. On the other hand an expansionary demand management policy (to combat recession) may not be as harmful for inflation as it was previously thought, as this paper suggests that supply shocks are the main contributors for the variation in inflation in most of the ASEAN countries considered. This finding also suggests that some supply side policies may be needed along with the inflation targeting policy to combat inflation.

This paper also found that the correlations of shocks across the 5 ASEAN countries are quite small, although some of these are statistically significant. This finding suggests that shocks are not synchronized in these countries and ASEAN countries are yet to be ready to form a common monetary union like Europe.

\section{References:}

Abeysinghe, Tilak and Gulasekaran Rajaguru (2004). "Quarterly GDP Estimates for China and ASEAN4 with Forecast Evaluation.” Journal of Forecasting 23, 431-47.

Ball, Laurence (1999). "Aggregate Demand and Long Run Unemployment." Brookings Papers on Economic Activity 2, 189-251.

Bayoumi, Tamim and Barry J. Eichengreen (1994). "One Money or Many? Analysing the Prospects for Monetary Unification in Various Parts of the World." Princeton Studies in International Economics 16, Princeton University. 
Bayoumi, Tamim; Barry J. Eichengreen, and Paolo Mauro (2000). "On Regional Monetary Arrangements for ASEAN." Journal of the Japanese and International Economies 14, 12148.

Blanchard, Olivier J (1987). "Why Does Money Affect Output: A Survey." NBER Working Paper Series, Paper No. 2285.

Blanchard, Olivier J. and Danny Quah (1989). "The Dynamic Effects of Aggregate Demand and Aggregate Supply Disturbances." American Economic Review 79, 655-73.

Blanchard, Olivier J. and Summers, Lawrence H. (1987). "Hysteresis in Unemployment." Europian Economic Review 31, 288-95.

Cover, James P., Walter Enders, and C. James Hueng (2006). "Using the Aggregate Demand-Aggregate Supply Model to Identify Structural Demand-side and Supply-Side Shocks: Results Using a Bivariate VAR.” Journal of Money, Credit and Banking 38, 777-90.

Lucas, Robert E, Jr (1972). "Expectations and the Neutrality of Money." Journal of Economic Theory 4, 103-24.

Lucas, Robert E, Jr (1973). "Some International Evidence on Output-Inflation Tradeoffs." American Economic Review 63, 326-34.

Mankiw, N. Gregory (1987). "The Optimal Collection of Seigniorage: Theory and Evidence." Journal of Monetary Economics 20, 327-41.

Ng, Thiam Hee (2002). "Should the Southeast Asian Countries form a Currency Union?" Developing Economies 40, 113-34.

Stadler, George W. (1990). "Business Cycle Models with Endogenous Technology." American Economic Review 80, 763-78.

Utterback, James, M. (1974). "Innovation in Industry and the Diffusion of Technology," Science 183, 620-26. 